\title{
Effect of roughage on rumen microbiota composition in the efficient feed converter and sturdy Indian Jaffrabadi buffalo (Bubalus bubalis)
}

Neelam M. Nathani ${ }^{1,3^{*}}$, Amrutlal K. Patel ${ }^{1}$, Chandra Shekar Mootapally ${ }^{1}$, Bhaskar Reddy ${ }^{1}$, Shailesh V. Shah ${ }^{2}$, Pravin M. Lunagaria ${ }^{2}$, Ramesh K. Kothari ${ }^{3}$ and Chaitanya G. Joshi ${ }^{*}$

\begin{abstract}
Background: The rumen microbiota functions as an effective system for conversion of dietary feed to microbial proteins and volatile fatty acids. In the present study, metagenomic approach was applied to elucidate the buffalo rumen microbiome of Jaffrabadi buffalo adapted to varied dietary treatments with the hypothesis that the microbial diversity and subsequent in the functional capacity will alter with diet change and enhance our knowledge of effect of microbe on host physiology. Eight adult animals were gradually adapted to an increasing roughage diet (4 animals each with green and dry roughage) containing 50:50 (J1), 75:25 (J2) and 100:0 (J3) roughage to concentrate proportion for 6 weeks. Metagenomic sequences of solid (fiber adherent microbiota) and liquid (fiber free microbiota) fractions obtained using lon Torrent PGM platform were analyzed using MG-RAST server and CAZymes approach.

Results: Taxonomic analysis revealed that Bacteroidetes was the most abundant phylum followed by Firmicutes, Fibrobacter and Proteobacteria. Functional analysis revealed protein (25-30 \%) and carbohydrate (15-20 \%) metabolism as the dominant categories. Principal component analysis demonstrated that roughage proportion, fraction of rumen and type of forage affected rumen microbiome at taxonomic as well as functional level. Rumen metabolite study revealed that rumen fluid nitrogen content reduced in high roughage diet fed animals and pathway analysis showed reduction in the genes coding enzymes involved in methanogenesis pathway. CAZyme annotation revealed the abundance of genes encoding glycoside hydrolases $(\mathrm{GH})$, with the $\mathrm{GH} 3$ family most abundant followed by $\mathrm{GH} 2$ and GH13 in all samples.

Conclusions: Results reveals that high roughage diet feed improved microbial protein synthesis and reduces methane emission. CAZyme analysis indicated the importance of microbiome in feed component digestion for fulfilling energy requirements of the host. The findings help determine the role of rumen microbes in plant polysaccharide breakdown and in developing strategies to maximize productivity in ruminants.
\end{abstract}

Keywords: Jaffrabadi rumen metagenome, roughage proportions, MG-RAST, CAZymes

\footnotetext{
* Correspondence: neelam.nathani@yahoo.com; cgjoshi@rediffmail.com ${ }^{1}$ Department of Animal Biotechnology, College of Veterinary Science \& Animal Husbandry, Anand Agricultural University, Anand, Gujarat 388 001, India

Full list of author information is available at the end of the article
} 


\section{Background}

'Superorganism' is the term coined to portray the association of symbiotic microbiota with its higher animal [1]. The microbes inhabiting the gut/ rumen are known to impose protective effects and nutritional benefits to the host [2] and due to its superior metabolic potentials compared to the host they are rightly considered equivalent to an organ [3-5]. In humans, microbes are found to comprise almost 3.3 million non-redundant genes, i.e. approximately 150 times higher than the number of genes in the human genome [6]. In ruminants, the significance of microbiome for maintaining host homeostasis was observed long before it was noticed in humans. Ruminant hosts are benefitted from microbial proteins and vitamins like metabolite produced by them. Ruminants obtain their energy due to the utilization of complex plant polysaccharides by microorganism, which are else indigestible by host. Domestication of ruminants has provided stable food supply and means of livelihood to thousands of people worldwide since earlier times. Ruminant meat and milk is considered as one of the most important agricultural products (FAO, 2009). Because of concomitant increase in food consumption, the demand for meat and milk is constantly increasing, further enhancing the need for sustainable number of ruminants (World Bank, 2008). Sustainable production of meat and milk requires an in-depth knowledge about the functions of the microbes and their interactions with the host. Nowadays, the high-throughput next generation sequencing technologies have alleviated studies such as metagenomics, metatranscriptomics, metaproteomics and metabolomics to characterize complex rumen microbial ecosystem and apply the information for improving forage digestion efficiency.

On the other hand, the feed composition also profoundly influences the microbial population [7, 8]. Ruminants possess a very complex microbial ecosystem comprising of bacteria, protozoa, fungi, methanogens and bacteriophages that well adapt to variable diets $[7,9]$. Their abundance in the rumen and the metabolic activity is reported to be remarkably high compared to terrestrial and aquatic ecosystems [10-13]. However, very few $(<15 \%)$ of the rumen bacteria are known to be cultured [14], highlighting the importance of molecular biology approaches like metagenomics to sidestep this limitation.

Ruminants are a crucial intermediate between light energy and the production of edible compounds such as milk and meat. Among them, buffalo plays a highly vital part of the Indian economy solely contributing for $>55 \%$ of total milk production by Indian livestock. Especially, the Jaffrabadi breed of buffaloes, which are mainly a native of Saurashtra region including the Junagadh, Bhavnagar, Jamnagar, Porbandar, Amreli and Rajkot districts of Gujarat are good milkers and one of the heaviest Indian breed. They efficiently convert roughage into milk and are found to be different compared to other breeds in the terms of its milk fat content [15]. Earlier reports have described use of rumen microbiota modulation for increasing the feed digestion efficiency $[16,17]$. Ruminants can degrade dietary fibers to short chain fatty acids with help of the inhabiting microbial consortium. In the process, ATP is generated that stimulates microbial growth, specifically the synthesis of cellular protein [18]. This can be an important attribution for improving the energy supply of rumen. Maximizing efficiency of its production would consequently improve cattle productivity. Nevertheless, knowledge of the functioning of rumen microbiome for example mechanism of plant polysaccharide degradation is still incomplete $[19,20]$. The evolution of the study of rumen microbial diversity similar to other microbial ecosystems has moved from culture-based microscopic studies to the use of culture-independent molecular techniques. Second-generation sequencing techniques have revolutionized the microbiome study by producing huge amount of data leading to increased coverage depth further permitting identification of even the less abundant community members $[21,22]$. Phylogenetically near microbes are reported to have varied metabolic potentials thus revealing the significance of characterizing complex microbial communities [23, 24]. Rumen microbiome studies of Indian cattle and buffalo is gaining much interest, however the Jaffrabadi breed rumen microbiome has not been well characterized. The objective of this study was to characterize and compare the rumen microbiome at taxonomic and metabolic level as well as to establish the database of the same for efficient feed converter and sturdy Indian breed of buffalo, Jaffrabadi (Bubalus bubalis) reared under varied dietary roughage proportions using metagenomic approach to better comprehend its correlation with nutrient utilization and maintenance of host homeostasis.

\section{Methods \\ Ethics Statement}

The experiment was performed under the approval of the institutional animal ethics committee of College of Veterinary Science \& Animal Husbandry, Anand Agricultural University vide letter no. AAU/GVC/CPCSEAIAEC/108/2013 dated 05/10/2013.

\section{Dietary Feed treatment}

In the present study, eight healthy adult (4-5 years old), non-pregnant, dry buffaloes of Jaffrabadi breed which had completed $1^{\text {st }}$ lactation and had an average body weight of 350-400 kg were included. All animals under study were reared at the Livestock Research Station, Anand Agricultural University, Gujarat, India. 
Before the experimental feed treatment, the animals were maintained under the feeding standards of the National Royal Commission (NRC). Out of eight animals under study, four were supplemented with green (G) fodder as roughage content and another four with dry (D) fodder as roughage content in total feed (roughage and concentrate). The nutrient composition of the feed were described in Additional file 1: Table S1. Considering the facts that if started with dietary treatment of $100 \%$ roughage (D/G), the microbial diversity lost due to low protein supplement may take a long time to recover when shifted to high protein diet, whereas if started with a $50 \%$ of roughage $(D / G)$, the available microbial diversity will start to adapt the less protein diet. Thus, in this study feeding regime included an increasing proportion of roughage (D/G) content at regular feed intervals. A total of three dietary treatments in the current study comprised a mixture of roughage $(R)$ and concentrate $(C)$ feed at ratios of 50:50 (J1),75:25 (J2) and 100:0 (J3). Each dietary treatment was continued for six weeks to permit microbial adhesion and adaptation to the same, the time duration also ensures less probability of the previous microbial diversity carry over effects. After six weeks, rumen sample was collected from animals using stomach tube and vacuum pump $3 \mathrm{~h}$ post feeding. The rest of the rumen fluid was then passed through muslin cloth, without pressure for separation of the liquid (L) and solid (S) fractions without any wash. The filtrate and the solid fraction were collected in sterile cryo vials and were stored at $-80{ }^{\circ} \mathrm{C}$ until metagenomic DNA extraction. Simultaneously, prior to filtration, a small proportion of the rumen fluid $(\sim 100 \mathrm{ml})$ was aliquoted in a bottle for total volatile fatty acid (TVFA) and ammonia estimation. TVFA was measured using the Markham's distillation apparatus, wherein the volatilized fatty acids in presence of oxalate was collected through condenser and calculated, and the nitrogen contents were measured by the Kjeldahl's method.

\section{Metagenomic DNA extraction}

Metagenomic DNA was isolated from liquid and solid rumen samples of all the three treatments ( 4 animals $\mathrm{x} 2$ roughage types $\mathrm{x} 3$ diet treatments $\mathrm{x} 2$ fractions: total 48 samples) using QIAmp DNA Stool Mini Kit (Qiagen, USA) with slight modification for the solid samples that included pretreatment of PBS buffer along with vortexing for an hour to release the bacteria adhered to the dietary fibers and minimize the plant DNA fraction during the extraction procedure. DNA quality and quantity was determined using a NanoDrop ND-1000 spectrophotometer (Thermo Fisher, USA) and on $0.8 \%$ agarose gel electrophoresis.

\section{Shotgun Sequencing of rumen microbiome}

Forty eight DNA shotgun bar-coded libraries from a start-up DNA concentration of $\geq 300$ ng of each sample were prepared as per standard 400 bp Ion Torrent PGM protocol (Life Technologies, USA). Four barcoded libraries of biological replicates from all the treatments were pooled on an equimolar basis. Emulsion PCR was carried out using the Ion OneTouch ${ }^{\text {TM }} 400$ Template Kit followed by enrichment of the Ion Sphere Particles (ISPs) as per the standard protocol. The enriched ISPs were loaded on the 316 chip, and sequencing run was performed. Twelve sequencing runs ( 4 barcoded libraries per run) were carried out on Ion Torrent PGM.

\section{Taxonomic and Functional analysis}

All metagenomic reads were uploaded on MG-RAST (Metagenomic Rapid Annotations using Subsystems Technology v3.2) for annotation purpose (http://meta genomics.anl.gov/) [25]. Host-specific reads were curtailed by screening the reads against the closest relative Bos taurus UMD v3.0, as published complete sequences for buffalo were unavailable in the database. Phylogenetic classification was performed against M5NR database with minimum e-value of $1 \mathrm{e}-5$ and minimum identity of $60 \%$. Each value obtained indicated the percentage/percent relative frequency of reads with predicted proteins and ribosomal RNA genes annotated to the indicated taxonomic level. Functional annotation was performed using the SEED database with a minimum e-value of $1 \mathrm{e}$ 5 and minimum identity of $80 \%$ at level 1 and level 2 . For all subsequent analysis, mean proportion of four animals maintained under same diet treatment were considered, unless mentioned otherwise.

\section{CAZymes mining from rumen metagenome}

The raw reads from four replicates were pooled and assembled into contigs using GS De Novo Assembler v2.3 with default parameters. The assembled contigs were uploaded in CAZymes Annotation Toolkit (CAT) at http://mothra.ornl.gov/cgi-bin/cat/cat.cgi for sequence based annotation with e-value of 1e-5 [26]. The results were further studied for recognizing the organisms contributing to coding sequences (CDS) for CAZymes.

\section{Statistical analysis}

Two-way Fisher's exact test with a Benjamin-Hochberg FDR multiple test correction was performed for statistical analysis between all the rumen microbiome samples at the taxonomic and functional level using the Statistical Analysis of Metagenomic Profiles, STAMP v1.07 software package for identification of biologically meaningful statistical differences between samples at different variable including treatment, fractions and diet [27]. Metabolism and CAZyme abundance were 
analyzed for statistical significance based on correlation test and ANOSIM (Analysis of Similarity) using PAST (Paleontology Statistics) software [28].

\section{Nucleotide sequence accession numbers of rumen Microbiome samples}

All the sequences were submitted to MG-RAST server for annotation (Details in Table 1).

\section{Results}

Metagenome sequencing of 48 samples using Ion torrent resulted into a total of 38 million raw reads and 27 million reads post quality filtering. The sequencing data of individual samples obtained after quality filtering are detailed in Table 1. Based on the MGRAST annotation, about 0.1 to $1.9 \%$ of the reads were classified as rRNA per rumen microbiome sample based on the hits against $16 \mathrm{~S}$ rRNA gene sequence databases while 73 to $90 \%$ of the reads from all the samples were classified into various functional subsystems.

Taxonomic distribution in the rumen microbiome samples At the domain level, bacteria were the most abundant with an abundance of $>90 \%$ in all the samples, followed by the eukaryotes $(\sim 3$ to $5 \%)$. Archaea were present in a proportion of $\sim 1 \%$, while the rest included unassigned sequences and the virus sequences.

\section{Effect of diet on microbial diversity}

The taxonomic assignment at phylum level using the M5NR database revealed dominance of the Bacteroidetes phyla in the rumen microbial community of liquid fraction of Green Roughage (GL) as well as the Dry Roughage (DL) diet fed animals (Fig. 1a). Firmicutes, Fibrobacter, Proteobacteria and Cyanobacteria were the other major phyla observed constituting about $80-85 \%$ of the total phyla across all the three, i.e. J1, J2 and J3 treatments. Rest 15 to $20 \%$ comprised of majorly unassigned sequences followed by other phyla including Actinobacteria, Chlamydiae, Spirochaetes, Tenericutes and Verrucomicrobia. Bacteroidetes were observed to be lower in the solid samples as compared to that in liquid samples, whereas the Fibrobacter and Firmicutes proportion was relatively higher. As the roughage proportion was increased from $50 \%$ to $100 \%$ there was decrease in the Bacteroidetes abundance across all the samples.

Similarly, at the genus level the two predominant genus of Bacteroidetes family, viz. Prevotella and Bacteroides were found decreasing with the increase in roughage proportion (Fig. 1b). Both were significantly (p-value $<0.05$ ) higher in the liquid as compared to solid portion (Fig. 1c). Out of the fourteen most abundant genera comprising about $70 \%$ of total genera, four were significantly varying across treatments and thirteen were varying between the solid and liquid fractions. Paludibacter and Victivallis were found increasing with the increase in roughage content. Allistepes was highest in J1, followed by J3 and then J2. Further at species level, Prevotella ruminicola was the predominant species in all the liquid samples throughout different treatments followed by the two important fibrolytic species of rumen ecosystem viz., Fibrobacter succinogenes and Ruminicoccus albus. In the solid fraction, Fibrobacter succinogenes and Ruminicoccus albus were predominant followed by Prevotella ruminicola.

\section{Roughage vs. Firmicutes/Bacteroidetes ratio}

Bacteroidetes and Firmicutes were the most prevalent phyla throughout the treatments. For the Firmicutes/ Bacteroidetes ratio, significant differences between liquid ( 0.3 to 0.59 ) and solid (0.6 to 1.1 ); as well as between the three treatments were observed for both green and dry roughage fed animals (Fig. 2). Notably specific trend was observed for green and dry diets, whereby in the green roughage fed animals the ratio was found to be higher in J1, reduced in $\mathrm{J} 2$ and again increased in the J3 treatment, whereas in dry roughage fed animals the ratio was found increasing with increase in roughage proportion $(\mathrm{J} 1>\mathrm{J} 2>\mathrm{J} 3)$.

\section{Diet and Correlation between various Phyla}

We checked for the cross-phylum interactions in the buffalo rumen among green and dry diet feeds. Phylum abundance profiles were determined across 12 rumen samples. Linear correlation test revealed negative correlation was observed between the Bacteroidetes and Fibrobacters phyla. During green roughage treatment results showed that the abundance of Bacteroidetes positively correlated with abundance of bacterial phylum Verrucomicrobiae, Proteobacteria and Tennericutes for both the treatments while negatively correlated with Fibrobacters, Firmicutes and Spirochaetes during the dry roughage treatment (Table 2).

\section{Functional diversity based on dietary changes}

Functional analysis at level 1 using the SEED database in MG-RAST revealed that the highest coding sequences were present for the protein metabolism followed by carbohydrate metabolism category. At level 1, about ten categories including secondary metabolite; nitrogen metabolism; DNA metabolism; protein metabolism; carbohydrates; amino acids and derivatives; sulfur metabolism; cofactors, motility and Chemotaxis; and miscellaneous were observed to be significantly different between the liquid and solid fractions (Fig. 3a). Among these, the abundance of all categories was more in the solid fraction except the carbohydrate and protein metabolism which was higher in the liquid portion, which clearly indicated the difference in the microbial diversity of both 
Table 1 Sequence details of 48 metagenomic samples

\begin{tabular}{|c|c|c|c|c|c|c|c|}
\hline Sample ID & MG-RAST Accession No. & Initial Reads & QC Passed Reads & rRNA Reads & Reads with predicted CDS & Post QC bp Count & a Diversity \\
\hline J1GL1 & 4604206.3 & $1,424,078$ & $1,173,142$ & 1,066 & $1,005,811$ & $229 \mathrm{MB}$ & 278.47 \\
\hline J2GL2 & 4604108.3 & 928,450 & 742,323 & 638 & 619,505 & $127 \mathrm{MB}$ & 322.03 \\
\hline J1GL3 & 4604092.3 & 512,016 & 423,203 & 390 & 368,554 & $77 \mathrm{MB}$ & 330.86 \\
\hline J1GL4 & 4571939.3 & 412,187 & 336,762 & 1,541 & 283,379 & $52 \mathrm{MB}$ & 422.45 \\
\hline J1GS1 & 4604096.3 & 498,599 & 412,088 & 535 & 353,673 & $74 \mathrm{MB}$ & 305.85 \\
\hline J1GS2 & 4604097.3 & 549,260 & 465,291 & 815 & 414,950 & $93 \mathrm{MB}$ & 226.21 \\
\hline J1GS3 & 4604098.3 & 677,970 & 562,220 & 820 & 494,011 & $111 \mathrm{MB}$ & 267.64 \\
\hline J1GS4 & 4604100.3 & 703,240 & 571,552 & 624 & 490,396 & $105 \mathrm{mb}$ & 293.22 \\
\hline J1DL1 & 4575792.3 & 949,870 & 636,956 & 5,020 & 516,485 & $106 \mathrm{MB}$ & 236.28 \\
\hline J1DL2 & 4575793.3 & 774,918 & 559,938 & 4,449 & 454,942 & $96 \mathrm{MB}$ & 215 \\
\hline J1DL3 & 4575794.3 & 918,259 & 673,358 & 5,722 & 546,797 & $115 \mathrm{MB}$ & 192.89 \\
\hline J1DL4 & 4575795.3 & 845,121 & 589,649 & 5,080 & 480,019 & $98 \mathrm{MB}$ & 238.12 \\
\hline J1DS1 & 4575901.3 & 708,081 & 451,811 & 2,716 & 355,948 & $72 \mathrm{MB}$ & 295.41 \\
\hline J1DS2 & 4575796.3 & 951,833 & 680,197 & 4,127 & 549,267 & $115 \mathrm{MB}$ & 309.42 \\
\hline J1DS3 & 4575797.3 & 641,328 & 463,939 & 2,576 & 386,658 & $79 \mathrm{MB}$ & 265.89 \\
\hline J1DS4 & 4575798.3 & 700,602 & 505,592 & 3,066 & 414,480 & $87 \mathrm{MB}$ & 271.48 \\
\hline J2GL1 & 4575799.3 & 505,950 & 311,420 & 1,779 & 250,659 & $47 \mathrm{MB}$ & 246.79 \\
\hline J2GL2 & 4575800.3 & 622,310 & 363,544 & 2,924 & 283,594 & $52 \mathrm{MB}$ & 272.56 \\
\hline J2GL3 & 4575801.3 & $1,029,049$ & 580,314 & 3,600 & 449,782 & $84 \mathrm{MB}$ & 216.72 \\
\hline J2GL4 & 4575802.3 & 752,725 & 428,414 & 2,834 & 330,438 & $62 \mathrm{MB}$ & 249.28 \\
\hline J2GS1 & 4575803.3 & 632,004 & 364,726 & 2,382 & 287,106 & $53 \mathrm{MB}$ & 198.09 \\
\hline J2GS2 & 4575804.3 & 723,939 & 405,675 & 2,573 & 315,656 & $59 \mathrm{MB}$ & 187.26 \\
\hline J2GS3 & 4575805.3 & 672,315 & 386,374 & 2,586 & 302,656 & $56 \mathrm{MB}$ & 188.61 \\
\hline J2GS4 & 4575806.3 & 625,425 & 359,933 & 2,566 & 278,956 & $53 \mathrm{MB}$ & 179.03 \\
\hline J2DL1 & 4575807.3 & $1,051,264$ & 753,416 & 10,146 & 631,726 & $148 \mathrm{MB}$ & 282.88 \\
\hline J2DL2 & 4603329.3 & 713,045 & 597,496 & 678 & 528,928 & $145 \mathrm{MB}$ & 343 \\
\hline J2DL3 & 4575809.3 & 986,698 & 722,822 & 9,061 & 609,515 & $144 \mathrm{MB}$ & 210.54 \\
\hline J2DL4 & 4575810.3 & 850,672 & 603,721 & 8,710 & 504,032 & $116 \mathrm{MB}$ & 320.17 \\
\hline J2DS1 & 4575811.3 & 840,552 & 588,345 & 9,514 & 473,773 & $108 \mathrm{MB}$ & 257.68 \\
\hline J2DS2 & 4575812.3 & 477,350 & 295,723 & 5,475 & 231,448 & $48 \mathrm{MB}$ & 314.28 \\
\hline J2DS3 & 4575813.3 & 615,868 & 389,436 & 7,503 & 302,586 & $62 \mathrm{MB}$ & 330.97 \\
\hline J2DS4 & 4618633.3 & 659,273 & 522,750 & 506 & 450,497 & $111 \mathrm{MB}$ & 347.89 \\
\hline J3GL1 & 4604101.3 & 652,383 & 552,242 & 603 & 490,170 & $55 \mathrm{MB}$ & 324.08 \\
\hline J3GL2 & 4575822.3 & $1,110,839$ & 796,087 & 8,867 & 621,768 & $140 \mathrm{MB}$ & 302.69 \\
\hline J3GL3 & 4575823.3 & 635,610 & 456,220 & 3,733 & 376,693 & $82 \mathrm{MB}$ & 261.99 \\
\hline J3GL4 & 4575824.3 & 730,149 & 533,490 & 3,910 & 439,428 & $97 \mathrm{MB}$ & 296.69 \\
\hline J3GS1 & 4575825.3 & 626,583 & 392,629 & 3,997 & 313,489 & $66 \mathrm{MB}$ & 244.66 \\
\hline J3GS2 & 4575826.3 & 669,967 & 456,754 & 3,937 & 375,022 & $81 \mathrm{MB}$ & 239.68 \\
\hline J3GS3 & 4575902.3 & 774,116 & 497,294 & 5,187 & 391,485 & $85 \mathrm{MB}$ & 276.19 \\
\hline J3GS4 & 4575897.3 & 715,753 & 470,224 & 4,152 & 385,107 & $83 \mathrm{MB}$ & 257.78 \\
\hline J3DL1 & 4575814.3 & 886,334 & 609,043 & 6,891 & 504,556 & $107 \mathrm{MB}$ & 332.67 \\
\hline J3DL2 & 4575815.3 & 703,305 & 512,015 & 5,212 & 437,145 & $90 \mathrm{MB}$ & 399.25 \\
\hline J3DL3 & 4575816.3 & 703,848 & 511,130 & 5,656 & 432,451 & $89 \mathrm{MB}$ & 386.36 \\
\hline J3DL4 & 4575817.3 & $1,072,487$ & 735,953 & 7,679 & 607,004 & $124 \mathrm{MB}$ & 373.05 \\
\hline
\end{tabular}


Table 1 Sequence details of 48 metagenomic samples (Continued)

\begin{tabular}{llllllll}
\hline J3DS1 & 4604102.3 & $3,651,797$ & $2,657,826$ & 2,473 & $1,941,947$ & $530 \mathrm{MB}$ & 217.07 \\
J3DS2 & 4575818.3 & 503,637 & 309,631 & 4,059 & 236,682 & $47 \mathrm{MB}$ & 171.43 \\
J3DS3 & 4575819.3 & 512,538 & 334,694 & 4,934 & 266,702 & $54 \mathrm{MB}$ & 218.68 \\
J3DS4 & 4575820.3 & 762,281 & 443,019 & 8,521 & 328,072 & $60 \mathrm{MB}$ & 318.59 \\
\hline
\end{tabular}

the fractions. Three of the categories viz. carbohydrates; amino acids and its derivatives; and miscellaneous differed significantly across the J1, J2 and J3 dietary treatments, wherein the coding sequences related to the Carbohydrate subsystem increased with the increase in roughage concentration (Fig. 3b).

Further based on the highest abundance of protein and carbohydrate metabolism, we studied the level 2 classification for these two subsystems. Protein metabolism included five different categories including protein biosynthesis, protein degradation, protein folding, protein modification and processing and selenoproteins (Fig. 3c). The abundance of all the categories except selenoproteins varied across the three treatments; green and dry diets as well as the liquid and solid fractions. We observed that the maximum sequences were attributed to the protein biosynthesis, followed by protein modification and processing. With increase in the roughage proportion, protein biosynthesis and degradation were found to be reducing while protein modification, processing and refolding were increasing. During the dry diet, protein biosynthesis was more abundant, while the degradation and folding were more expressed in green diet. All the categories except protein processing and modification were more expressed in the solid fraction as compared to the liquid fraction.

Similarly, the carbohydrate metabolism included ten sub categories, among which the central carbohydrate metabolism, amino sugars and polysaccharides metabolism did not vary across the samples (Fig. 3d). One carbon metabolism, organic acids and sugar alcohol were least in the $\mathrm{J} 2$ treatment compared to J1 and J3. While monosaccharide and oligosaccharides metabolism, fermentation and $\mathrm{CO}_{2}$ fixation was highest in the $\mathrm{J} 2$ treatment. All the categories were more abundant in the dry treatment compared to the green treatment. Among the two fractions, solid fraction gave more hits to the functional category as compared to the liquid fractions.

Further, to understand the similarity/variation among the microbiome composition of all the samples, principal components analysis (PCA) was performed for between groups correlation based on taxonomic and functional annotation. Principal component analysis (PCA) of showed that the samples fed on same treatment (J1, J2

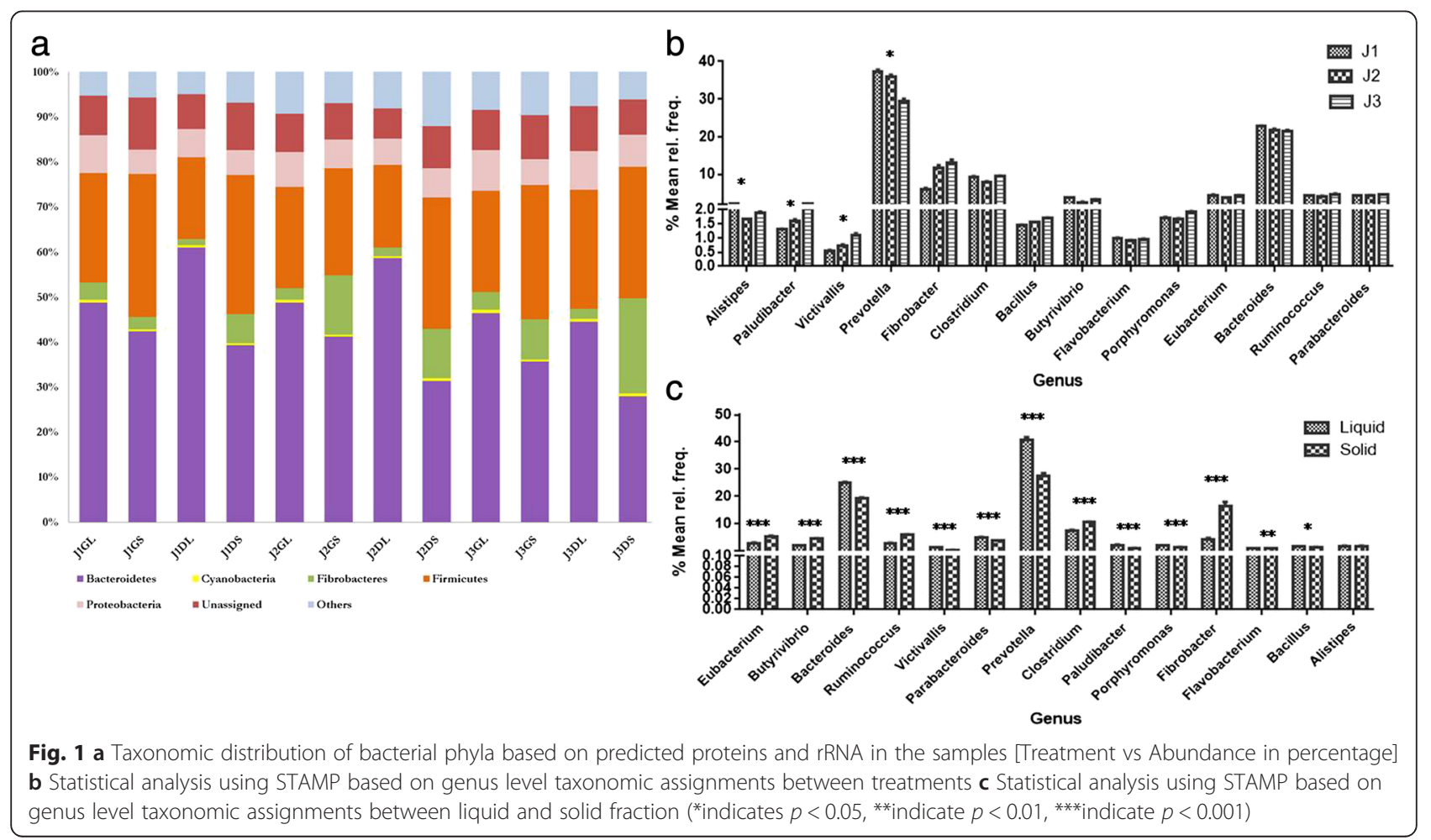




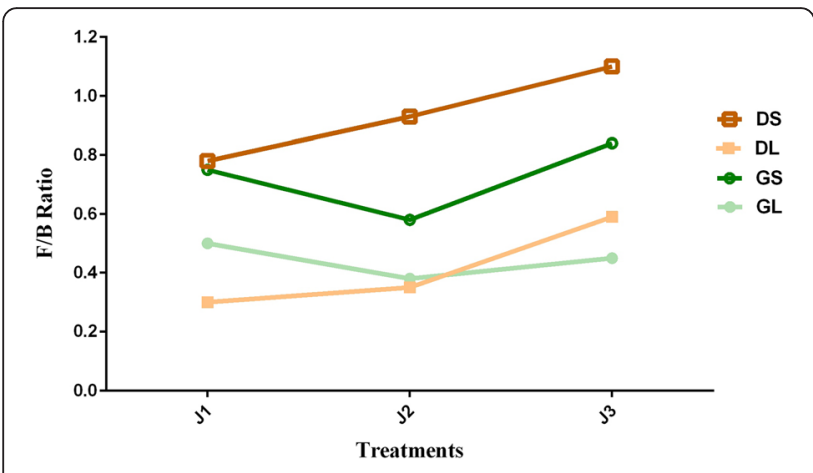

Fig. 2 Firmicutes/Bacteroidetes ratio during the three treatments

and J3) clustered together (Fig. 4). Samples from each treatment of green and dry roughage fed animals tended to cluster together, signifying that related functions were encoded in their metagenome during respective treatments.

\section{Diet impact on Rumen Metabolism}

In our study, to determine the effect of change in feed on rumen metabolism, we performed whole rumen fluid analysis. The total- $\mathrm{N}$ and ammonia- $\mathrm{N}$ concentrations in the rumen fluid were found decreasing significantly $(p<0.05)$ in the dry roughage fed animals with increase in the roughage proportion viz. from J1D to J3D. Also, the concentrations of total $-\mathrm{N}$ and ammonia- $\mathrm{N}$ were relatively higher in the green roughage fed individuals as compared to the dry roughage fed individuals. Soluble $\mathrm{N}$ was significantly higher in J1 as compared to J2. The concentration of Non Protein Nitrogen (NPN) was found to be significantly higher in green roughage fed individuals as compared to dry roughage fed. The concentration of NPN also significantly decreased with increase in the roughage proportion $(\mathrm{J} 1>\mathrm{J} 2>\mathrm{J} 3)$ for both green as well as dry roughage fed individuals. The Volatile Fatty Acid (VFA) concentrations did not show significant variation, though they were observed to be relatively higher in J1 and J3 compared to J2, but the difference was statistically nonsignificant (Table 3).
Dietary effect on volatile fatty acid (VFA) production

Environmental gene tags (EGTs) involved in production of volatile fatty acids viz. propanoate and butanoate were studied to check the effect of different diets on the same as (Pathway illustrated in Additional file 2: Figure S1). The results showed that the EGTs for propanoate were abundant in the first treatment and nearly likewise represented during the second and third treatment. Results also revealed that the propanoate production via 2hydroxy butyrate was better represented as compared to the Succinate pathway.

Similarly, EGTs corresponding to the butanoate production pathway were also determined throughout the dietary treatments. The biosynthesis pathway for butanoate production involves the final step for butanoate formation from butanoyl CoA via two possible pathways (Additional file 3: Figure S2). The results showed that the EGTs for butanoate were abundant in the J1 treatment subsequently followed by J3 and J2 treatments, except the EGTs for phosphate butyryl transferase and butyrate kinase enzymes responsible for the final butanoate production which were comparatively more abundant in the J2 than the J3 treatment.

\section{Dietary effect on Methanogenesis pathway}

We also considered the effect of three different dietary treatments on the proportion of EGTs involved in methane production (Additional file 4: Figure S3). The entire anaerobic process of methane formation takes place by the methanogenic archaea population in the rumen. EGTs for enzymes involved in methanogenesis were abundant in J1 followed by J2 and J3 treatment. Thus, increase of roughage proportion in the diet reduces the active genes for production of methane.

\section{Diet based variation in CAZymes distribution}

Results of the CAZyme Analysis Tool (CAT) revealed that the most encoded CAZyme domain included the Glycoside Hydrolase (GH) family ( $50 \%$ of total assignment), followed by the Carbohydrate Binding Modules (CBM) ( 30 \%), Glycosyl Transferases (GT) ( 15 \%) and

Table 2 Correlation between various phyla using PAleontologicalSTatistical analysis among Green Roughage fed animals

\begin{tabular}{|c|c|c|c|c|c|c|c|}
\hline $\begin{array}{l}\text { Dry } \\
\text { Green }\end{array}$ & Bacteroidetes & Fibrobacter & Firmicutes & Proteobacteria & Spirochaetes & Tenericutes & Verrucomicrobia \\
\hline Bacteroidetes & - & $-0.876^{* *}$ & -0.437 & 0.369 & -0.552 & 0.386 & 0.429 \\
\hline Fibrobacter & -0.569 & - & 0.586 & -0.378 & 0.727 & -0.477 & -0.519 \\
\hline Firmicutes & 0.404 & 0.022 & - & 0.318 & $0.772^{*}$ & 0.151 & 0.165 \\
\hline Proteobacteria & $0.897^{*}$ & -0.258 & 0.244 & - & 0.334 & $0.945^{* * *}$ & $0.978^{* * *}$ \\
\hline Spirochaetes & 0.661 & 0.087 & 0.591 & 0.810 & - & 0.162 & 0.165 \\
\hline Tenericutes & $0.865^{*}$ & -0.540 & -0.047 & $0.912^{* *}$ & 0.568 & - & $0.966^{* * *}$ \\
\hline Verrucomicrobia & 0.809 & -0.315 & -0.039 & 0.932 & 0.647 & $0.953^{* *}$ & - \\
\hline
\end{tabular}

Note: *indicates $\mathrm{p}<0.05,{ }^{* *}$ indicate $\mathrm{p}<0.01,{ }^{* * *}$ indicate $\mathrm{p}<0.001$ 


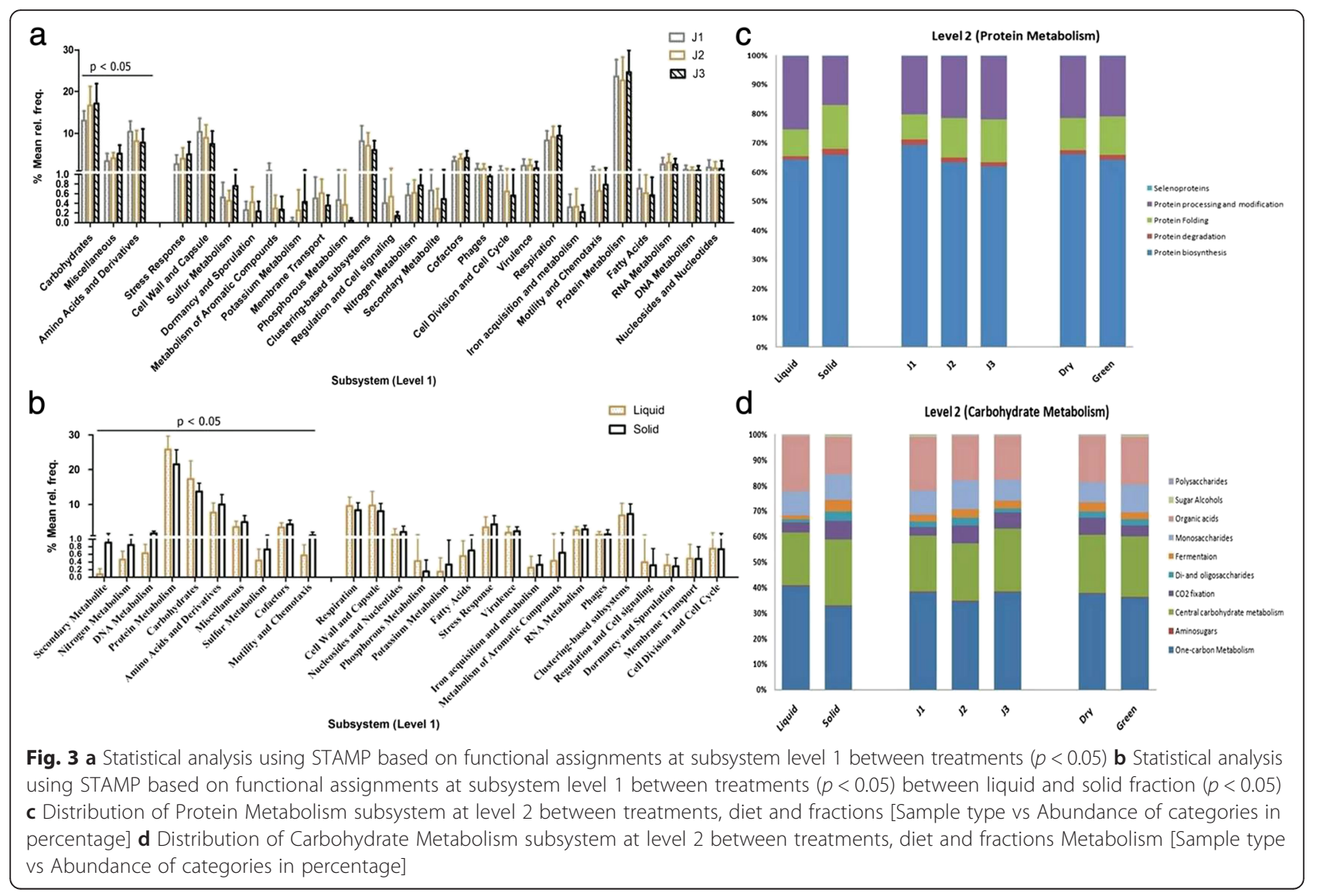

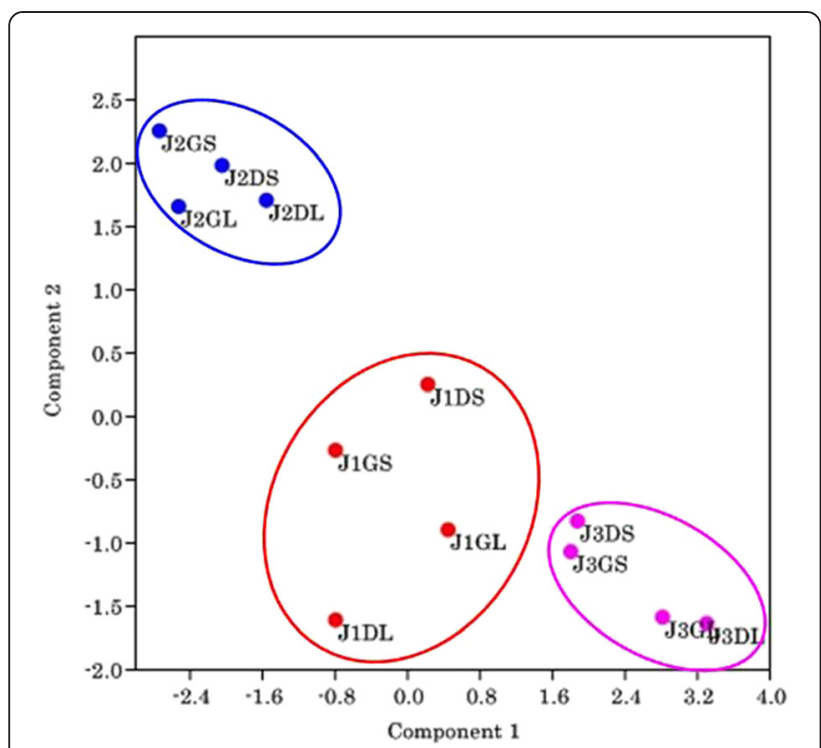

Fig. 4 Principal component analysis based on taxonomic (phylum level) and functional distribution in each sample using PAST a rest of the proportion ( $\sim 5 \%)$ comprising Pectate Lyases (PL) and Auxiliary Activities (AA) (Additional file 5: Figure S4). The proportion of GH family was found to increase marginally with increase in the roughage proportion for the dry fed individuals. GT family was represented more in the liquid samples as compared to the solid samples.

GH family can be further classified based on the functional role of the enzymes such as degradation of oligosaccharide, cellulose, hemicelluloses, pectin and other plant polymers. The contigs were found to comprise sequences related to a total of 52 different $\mathrm{GH}$ families amongst which majority included those playing role as oligosaccharide degrading enzymes (18 families) followed by debranching enzymes ( 8 families), cellulose degrading endohemicellulases (7 families) and cellulases (5 families), and cell wall elongation related enzymes (3 families) (Fig. 5). Out of these, oligosaccharide degrading GH2, GH3, GH18, and cellulase families GH5 and GH9 were most highly represented. The abundance of the GH families encoding gene varied with respect to the treatments; green and dry diet; as well as the solid and liquid fractions. Among the cellulases, GH5 and GH9 were the most abundant and were found to be more in the solid phase as compared to the liquid phase irrespective of diet, 
Table 3 Analysis of variance showing the effect of diet on various metabolites

\begin{tabular}{|c|c|c|c|c|c|c|c|}
\hline \multirow{2}{*}{$\begin{array}{l}\text { DietaryTreatment } \\
\text { Metabolite }\end{array}$} & & \multicolumn{2}{|l|}{$\mathrm{J1}(50 \mathrm{R}: 50 \mathrm{C})$} & \multicolumn{2}{|l|}{$\mathrm{J} 2(75 \mathrm{R}: 25 \mathrm{C})$} & \multicolumn{2}{|l|}{ J3 (100R:0C) } \\
\hline & & Dry & Green & Dry & Green & Dry & Green \\
\hline \multirow[t]{4}{*}{ Nitrogen Content(mg/dL) } & Total N & $77.7^{\mathrm{aA}} \pm 5.8$ & $147.7^{b} \pm 14.01$ & $63.49^{B} \pm 6.63$ & $64.75 \pm 6.12$ & $25.55^{{ }^{C C}} \pm 1.55$ & $48.55^{d} \pm 9.36$ \\
\hline & Ammonia N & $8.22^{\mathrm{aA}} \pm 0.25$ & $20.75^{b} \pm 1.05$ & $7.21^{B} \pm 1.23$ & $10.61 \pm 1.84$ & $3.08^{\mathrm{aC}} \pm 0.37$ & $11.62^{b} \pm 1.12$ \\
\hline & Soluble N & $21.98^{\mathrm{A}} \pm 0.54$ & $37.24^{C} \pm 1.39$ & $14.42^{B} \pm 1.38$ & $14.07^{D} \pm 0.83$ & $11.26 \pm 0.49$ & $12.67 \pm 0.7$ \\
\hline & NPN & $42.42^{\mathrm{aA}} \pm 0.77$ & $53.2^{\mathrm{bD}} \pm 2.93$ & $25.2^{\mathrm{CB}} \pm 2.54$ & $29.12^{\mathrm{dE}} \pm 2.71$ & $14.7^{\mathrm{eC}} \pm 1.24$ & $23.1^{\mathrm{fF}} \pm 1.2$ \\
\hline Total VFA(mM/L) & & $4.48 \pm 0.51$ & $4.67 \pm 0.29$ & $4.34 \pm 0.4$ & $4.55 \pm 0.72$ & $5.33 \pm 0.3$ & $5.5 \pm 0.17$ \\
\hline
\end{tabular}

Mean values in the same row with different superscripts (Capital case for between treatment; small case for between Dry/Green) differed significantly $(P<0.05)$

except for the GH5 in J1 treatment wherein it was more abundant in liquid compared to the solid phase. For the liquid phase the abundance of the former two families was more in the green diet fed individuals as compared to the dry fed. While for the solids the trend was found to be different viz. less in green compared to dry. Increasing the roughage proportion increased the cellulase encoding EGTs in the solid phase of both green and dry diet fed individuals, whereas for the liquid the abundance was higher in J1, reduced in J2 and again increased in J3. Similarly the endohemicellulases were found to be more abundant in the solid phases as compared to liquid, except for the GH12 and GH28 families which were almost negligible in the solid samples, with increase in the roughage (i.e. during the J2 and J3 treatments). Majority of the GH families in oligosaccharide degradation were more abundant in the liquid and well represented in the J1 and J3 treatments as compared to the J2 treatment except GH3, GH43, GH35,

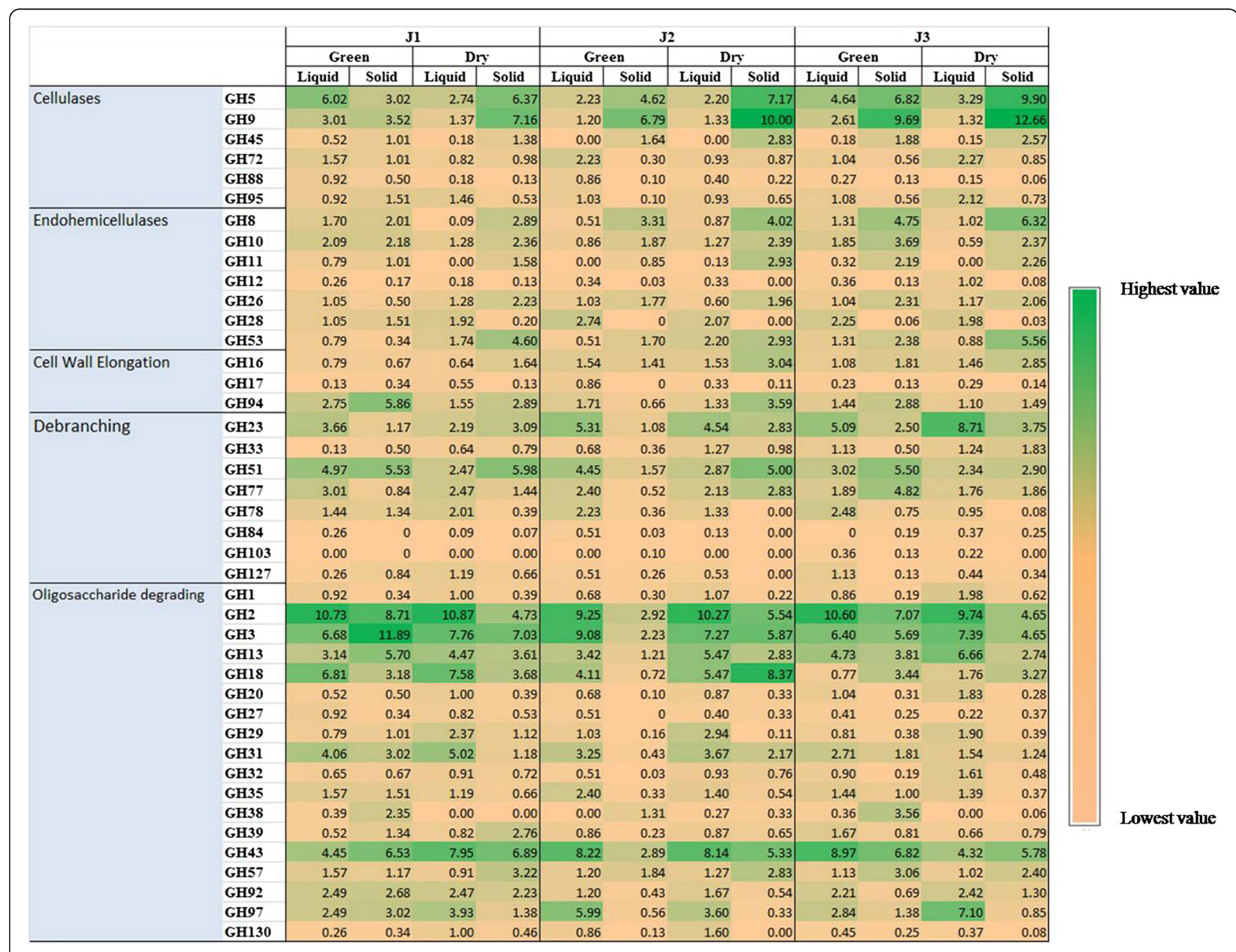

Fig. 5 Glycosyl Hydrolase family distribution (Pooled de novo assembly of 4 animals maintained under same diet treatment was considered) 
GH39, GH97 and GH130 which had slightly higher proportion in J2GL. The results thus reflect that diet has an impact on the microbial diversity further resulting in variability of the CAZyme families present in the studied samples.

We studied the taxonomy of the organism coding the $\mathrm{GH}$ families at genus level.

While in the green roughage fed individuals, there was enrichment of major microbial communities involved in encoding GH during the $75 \%$ roughage diet for liquid fraction, except for Bacteroides that were least during the J2DL treatment (Fig. 6a). In the solid samples, Fibrobacter were most abundant in J2, while Prevotella, Bacteroides and Clostridium were least. Hence, based on the results it is evident that Prevotella and Fibrobacters genus is the most active in terms of genes encoding CAZymes and hence can be exploited for industrial purposes.

In the dry roughage fed individuals, it was clearly observed that Prevotella was dominant in the liquid fractions and Fibrobacter in the solid (Fig. 6b). Also with increasing roughage the $\mathrm{GH}$ encoded by Prevotella reduced for both solid and liquid. Also in the liquid samples, the Ruminicoccus genus was observed much higher in J2 and J3 as compared J1, whereas in solid it was found to be more in J1 and then reduced in J2 and J3. The Fibrobacter genus was found to be coding more enzymes with increased roughage diet. The Chitinophaga genus was abundant in J2 treatment and Clostridium in J1 treatment for both the fractions. Bacteroides genus was less in the J2DS samples as compared to J1DS and J3DS, while it was highest in J1DL followed by J2DL and then J3DL.

\section{Discussion}

Ruminants entirely depend on their microbial community for feed digestion. Hence, appealing a hypothesis that there exists a strong correlation between the microbes and the host physiology focusing on nutrition availability and development. Understanding of the rumen microbiome has comprehensive implications like effect on methane production by rumen methanogens to host health maintenance and animal production [29-31]. Rumen microbiome of the sturdy Jaffrabadi breed buffalo native of the western India has not been deeply characterized as yet, especially by using the metagenomic approach.

In context to the same, present study focused exploration of diet dependent variation in the rumen bacterial community composition and functional characterization of 48 rumen samples of Jaffrabadi breed. Four animals as biological replicates were considered to evaluate effect of different proportions of green and dry roughage so that any considerable animal to animal microbiome variation can also be observed. However, as previously reported we observed lower variation between replicates [32]. We analyzed the effect of increased roughage proportion in diet on fiber adhered and fiber free microbial populations and found that particular taxa are enriched/suppressed with the change in diet and the functional abilities related to fulfilling host energy requirements are correlated with the abundance of various bacterial taxa.

\section{Effect of diet on microbial diversity}

Bacteroidetes, Firmicutes, Fibrobacter and Proteobacteria were the four dominant phyla observed in the present study. The results were similar to several of the earlier mammalian gut/rumen microbiota studies [33-36]. The Bacteroidetes were the most abundant phyla in majority samples, while few of the solid fraction samples had dominance of Firmicutes, similar to the earlier results observed in bovine rumen [37, 38]. Reports have also revealed that the increase of fibrous content in diet increased the Firmicutes abundance and decreased the Bacteroidetes population in the gut microbiota, as also observed in our results [37, 39]. The abundance was evident at the genus level also, where the Prevotella and Bacteroides genus dominated. Bacteroides group depend on the soluble polysaccharides released in liquid phase
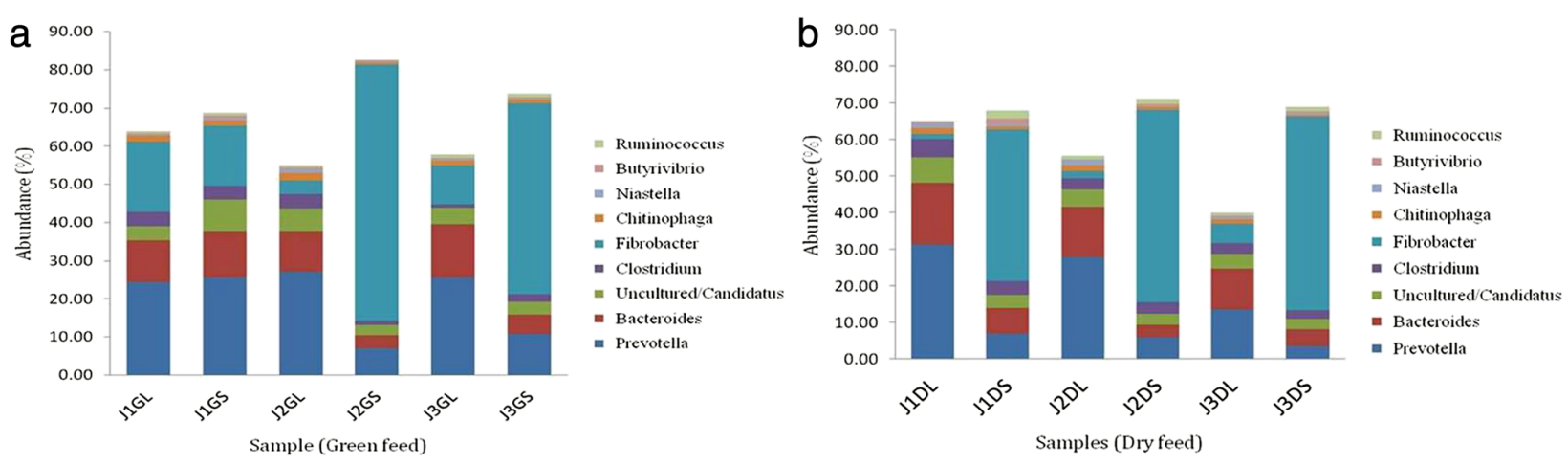

Fig. 6 Taxonomic distribution at genus level of microbes encoding genes for predicted CAZyme [Treatment vs Abundance in percentage] (a) Green roughage fed animals (b) Dry roughage fed animals 
of rumen by the activities of other bacteria [40, 41]. Prevotella have been shown to be involved in volatile fatty acid production like propanoate further used for energy by the host [42]. Increased Prevotella abundance could also be a reason in reducing methanogenesis as reported in a companion experiment [30, 43]. Along with Bacteroidetes, Firmicutes was one of the most abundant phyla in the rumen. At genus level, Clostridium, Ruminococcus and Butyrivibrio were the most represented Firmicutes. They are potent cellulose degraders as well as have the ability to digest pectin and hence are important component in the rumen dietary fiber utilization [44]. Bacteroidetes and Firmicutes population in the rumen and gut collectively involve in the conversion of organic matter to simpler forms $[45,46]$. The solid fraction favored Fibrobacteres, suggesting their importance in fiber degradation similar to the results of microbiome analysis of cattle fed Pasteur diets. However the results were contradictory to those reported earlier in mammalian guts, where the abundance was more in liquid fractions [34, 37].

\section{Roughage vs. Firmicutes/Bacteroidetes ratio}

The Firmicutes to Bacteroidetes ratio has been considered an important parameter to assess the microbe impact on host energy requirements [8, 31, 47]. As observed the Firmicutes are increasing with the increase in roughage proportion while the Bacteroidetes population tends to decrease specifically during the dry fed diet. This leads to the increase in the F/B ratio, similar to the earlier reports where a shift from grain to fiber rich diets led to an increase in the ratio [31, 34, 48].

\section{Diet and Correlation between various Phyla}

Microorganisms in natural environments are often involved in commensal or mutualistic interactions. Specifically, in the rumen significant interspecies cross feeding of intermediate products has been observed among the adherent and non adherent bacteria population [49]. Other interactions also include that between the carbohydrate fermenting bacteria which requires volatile fatty acids provided by the amino acid degrading ruminal bacteria [50]. In our study, we observed that the fibrolytic phyla Fibrobacter and Firmicutes positively correlated with the Spirochaetes. Studies have reported that co-culture of $F$. succinogens and a Spirochaete species Treponema enhanced fermentation of barley straw than a pure F. succinogens culture. Also, Spirochaetes decarboxylate the succinate formed by Fibrobacter into VFA which in turn serves as an important energy source to the host animal [51]. Results also revealed that Bacteroidetes positively correlated with the Verrucomicrobia, Proteobacteria and Tenericutes whereas negatively correlated with the cellulolytic Fibrobacters and Firmicutes. Previous studies on bovine rumen have reported Bacteroidetes to be negatively correlated with Firmicutes [31, 34].

\section{Functional diversity based on dietary changes}

Functional metagenomics has paved the way in assessing potential metabolic activities of the rumen microbiome. The MG-RAST results suggest that protein metabolism had the highest hits followed by carbohydrate and both increased with increase in the roughage proportion. Initial colonization in ruminants is of the organisms possessing the enzymes to act on the side chains of complex plant polysaccharides followed by their complete degradation in the fluid fraction of rumen. Nitrogen metabolism was abundant in $\mathrm{J} 3$ followed by $\mathrm{J} 1$ and J2. At low protein diet, rumen bacteria are inclined to exploit an alternate source to fulfill the nitrogen requirement of host. Similar results were also observed in bovine rumen microbiome [38]. In fiber diet both leguminous and non leguminous plants are present and hence the bacteria can trap ammonia- $\mathrm{N}$ in the form of bacterial protein and their digestion supplies the needed amino acids to the host [37]. Significant difference in the solid and liquid fractions for nitrogen metabolism might indicate better interaction of fibrous legumes and nitrogen utilizing bacteria in the solid phase. Sulfur increased the efficiency of nitrogen utilization for animals consuming a fescue hay-based diet [52]. We also observed similar results in our study.

Further analysis at level 2 in protein metabolism, results stated that protein biosynthesis was dominant in all the samples, confirming that microbial protein synthesis acts as a major source of protein for ruminants [53]. In carbohydrate metabolism, the genes associated with onecarbon metabolism, involving methane metabolism category at level 3 were abundant. These were most abundant in the J1 treatment suggesting that methanogenic archaea tends to decrease with high roughage diet. This could also be on account of the subsequent decrease in $\mathrm{pH}$ [54]. The genes associated with $\mathrm{CO}_{2}$ fixation and central carbohydrate metabolism increased with roughage.

To assess the correlation among bacterial phyla, PCA was performed based on taxonomic and functional annotation. Overall, PCA according to the taxonomic and functional assignment of major categories showed that samples from dry and green roughage fed individuals of each treatment tended to cluster together, indicating that a similar set of functions were encoded in their metagenome.

\section{Diet impact on Rumen Metabolism}

The estimation of VFA and various nitrogen moieties is necessary to track the microbial metabolism leading to the production of these compounds. VFA are extremely 
important as they endow more than $70 \%$ of ruminants energy supply. Large proportion of the natural food proteins release ammonia, which is utilized by the rumen microbes for their growth and synthesis of microbial protein. VFA produced by microbial action in the rumen are absorbed by the epithelium and further carried to the liver via the blood circulatory system. This continuous absorption of VFA maintains the ruminal $\mathrm{pH}$. In the present study, VFA concentration was highest in the low roughage fed individuals. There are similar reports with high VFA concentration in buffaloes [37, 55]. However, overall the concentration of VFA measured was comparatively lower compared to the earlier reports. The rumen microbiota converts ammonia into amino acids which is further accumulated as microbial protein. Total nitrogen was significantly different between the green and dry groups, indicating that the change in feed from green roughage to dry roughage led to significant change in the nitrogen content of rumen fluid. Also the $\mathrm{N}$ concentration was reduced from first treatment to the third. Similar differences in $\mathrm{N}$ content were observed in Mehsani buffalo fed on different diets and proportion of roughage [37]. Similar trend was observed for the NPN, soluble $\mathrm{N}$ and the ammonia $\mathrm{N}$. The concentrations decreased with high roughage indicating enhanced consumption of nitrogen and higher microbial proteins synthesis.

\section{Dietary effect on volatile fatty acid (VFA) production}

Rumen microbiome produces volatile fatty acids such as propionic acid, butyric acid and acetate by microbial fermentation, which in turn maintains the animal health and homeostasis. The VFAs are utilized further for milk and meat production contributing a major portion of the daily energy requirement of ruminants [56]. In our study, for propanoate production, out of the three plausible pathways, succinate pathway dominated. Similar to our results, several studies have reported that succinate pathway is considerably the most commonly used pathway by gut bacteria for propanoate production in mammals as well as humans $[57,58]$. Propanoate production was well represented during all the three treatments, but maximum hits were observed during the first treatment. The observed results could be due to the high prevalence of Bacteroidetes during the first treatment [59]. Earlier reports on bovine rumen have stated that propanoate production increases in rumen at the expense of acetate and butyrate with increase in abundance of Prevotella sp. [60]. Similarly, butanoate production was also found to be well represented during the first treatment followed by second and third treatment, which is contradictory to that observed in Kankrej rumen where the production was lesser in equal proportion of roughage to concentrate compared to $75 \%$ roughage diet [34].
Butanoate plays an important role in animal health by regulating the host physiology and as a signal molecule modulating cell properties like differentiation, proliferation and apoptosis [61].

\section{Dietary effect on Methanogenesis pathway}

Methane production is an issue of immense concern worldwide for its role as a greenhouse gas [62]. Various sources of methane emission exist such as wetlands, energy sectors, biomass burning, landfills and ruminants [63] among which the enteric fermentation constitutes to be the largest source [64]. Alleviation of methane by studying the rumen archaea metabolism may contribute to devising strategies to decrease the greenhouse effect [65]. In this perspective, we determined the EGTs involved in methanogenesis and effect of each treatment on the same. Results reveal that an increase in roughage proportion reduced the EGTs involved in methanogenesis. The results are similar to previous studies on Gir cattle where similar decrease in methane production was observed with increase in roughage rich diet (Unpublished data).

\section{Diet based variation in CAZymes distribution}

The potential to digest the coarse feed into metabolic energy in rumen is entirely attributed to its polysaccharide degrading enzymes. Rumen fluid due to its complex lignocellulosic degradation system is thus an excellent sample for mining CAZymes $[38,66]$. In our study, oligosaccharide degrading enzymes were the most abundant of the total glycoside hydrolases. The higher occurrence of this category is justified due to their action on large number of oligosaccharides byproducts generated after initial breakdown of the complex polysaccharides like cellulose, hemicellulose, and pectin. Among the GHs, GH2 that corresponds for glucuronidase and $\mathrm{GH} 3$ corresponding for L-arabinofuranisidase, B-D-glucosidase and B-Dxylopyranosidase activities were the most abundant. The major source for GH3 is known to be Prevotella genus and hence we could observe that the proportion of GH3 encoding sequences decreased in the DL samples from J1 to $\mathrm{J} 3$ in correspondence to the decrease in Prevotella population as seen from the genus level classification of organisms encoding the GH genes [67]. Modifying the diet to higher roughage proportion has been found to decrease the amylase activity in most reports $[37,68]$. Here we also observed similar trend whereby the GH13, 57 and 77 were reducing from $\mathrm{J} 1$ to $\mathrm{J} 3$. The presence of $\mathrm{GH} 43$ indicates microbial degradation of hemicellulose and xylose in rumen as this includes the $\alpha$ - $\mathrm{L}$-arabinofuranosidases, endo- $\alpha$ - $\mathrm{L}$-arabinanases and $\beta$ - $\mathrm{D}$-xylosidases. Variations in the abundance pattern of CAZy families among the green and dry roughage groups of the three treatments reveal the modulating microbial diversity with respect to feed as 
also observed from the abundance study on organisms involved in encoding these CAZymes.

\section{Conclusions}

The findings of the present study reveal that dietary changes have a significant impact on rumen microbiome at taxonomic as well as functional levels. It also leads to change in the VFA production as well as on methanogenesis with increase in the roughage proportion of diet, subsequently having impact on the host as well as at the global level. Additionally, the findings also reveal that high roughage diet enhances the PEGs involved in microbial protein synthesis and reduces those involved in methane formation. The information generated may allow us to modulate the rumen microbiome by providing a formulated diet with high dry roughage proportion and limiting the amounts of elements in diet that are mandatory for enzymes involved in methanogenesis. This would ultimately improve livestock nutrient utilization efficiency for better agricultural yield and have a global impact on environment by controlling the emission of methane gas. The study enhances the overall understanding of Jaffrabadi buffalo rumen microbial ecology affected by diet, allowing us to explore the link between microbial metabolism and host physiology.

\section{Availability of Supporting Data}

All the supporting data are included as additional files.

\section{Additional files}

Additional file 1: Table S1. Detailed composition of the diet fed. (DOCX $11 \mathrm{~kb}$ )

Additional file 2: Figure S1. Propanoate (VFA) production pathway (Abundance of enzymes during three treatments shown in parentheses). (JPG $365 \mathrm{~kb}$ )

Additional file 3: Figure S2. Butanoate (VFA) production pathway (Abundance of enzymes during three treatments shown in parentheses). (JPG $691 \mathrm{~kb}$ )

Additional file 4: Figure S3. Methanogenesis pathway (Abundance of enzymes during three different treatments shown in parentheses). (JPG $320 \mathrm{~kb}$ )

Additional file 5: Figure S4. CAZyme family distribution throughout treatments (Animal replicates pooled). (JPG $644 \mathrm{~kb}$ )

\section{Abbreviations \\ CAZymes: Carbohydrate Active Enzymes; CAT: CAZyme Analysis Toolkit; CDS: Coding Sequence; D/G: Dry or green diet; EGTs: Environmental Gene Tags; GH: Glycosyl Hydrolase; J: Jaffrabadi; L/S: Liquid or solid fraction of rumen fluid; NPN: Non Protein Nitrogen; PCA: Principal Components Analysis; PEGs: Protein Encoding Genes; VFA: Volatile Fatty Acid.}

\section{Competing interests}

The authors declare no financial or non financial competing interests.

\section{Author' contributions}

NMN and MCS: Performed the analysis and drafted the manuscript. AKP: Participated in statistical analysis and corrected the manuscript. BR: Carried out the experimental procedures. SVS and PML: Maintained the animals and performed the dietary feed treatments. RKK: Helped in improving the analysis from the microbial aspect and checked manuscript for improving its technicality and language proficiency. CGJ: Conceived of the study, participated in its design and coordination. All authors have read and approved the final manuscript.

\section{Acknowledgments}

The authors would like to thank Dr. Ramesh Menon for his thorough proofreading and valuable suggestions that helped improve the manuscript. This work was financially supported by the Niche area of excellence program on Metagenomic analysis of ruminal microbes funded by Indian Council of Agricultural Research (ICAR), New Delhi, India. The authors are thankful to Department of Science and Technology, Government of India for providing grant to NMN in the form of INSPIRE fellowship.

\section{Author details}

${ }^{1}$ Department of Animal Biotechnology, College of Veterinary Science \& Animal Husbandry, Anand Agricultural University, Anand, Gujarat 388 001, India. ${ }^{2}$ Livestock Research Station, Anand Agricultural University, Anand, Gujarat 388 001, India. ${ }^{3}$ UGC-CAS Department of Biosciences, Saurashtra University, Rajkot 360 005, Gujarat, India.

Received: 18 September 2015 Accepted: 22 December 2015 Published online: 29 December 2015

References

1. Goodacre R. Metabolomics of a superorganism. J Nutr. 2007;137(1 Suppl): 259S-66S.

2. Hooper LV. Bacterial contributions to mammalian gut development. Trends Microbiol. 2004;12(3):129-34. doi:10.1016/j.tim.2004.01.001.

3. Egert M, de Graaf AA, Smidt H, de Vos WM, Venema K. Beyond diversity: functional microbiomics of the human colon. Trends Microbiol. 2006;14(2): 86-91. doi:10.1016/j.tim.2005.12.007

4. Gill SR, Pop M, Deboy RT, Eckburg PB, Turnbaugh PJ, Samuel BS, et al. Metagenomic analysis of the human distal gut microbiome. Science. 2006; 312(5778):1355-9. doi:10.1126/science.1124234.

5. Xu J, Gordon JI. Honor thy symbionts. Proc Natl Acad Sci U S A. 2003; 100(18):10452-9. doi:10.1073/pnas.1734063100.

6. Qin J, Li R, Raes J, Arumugam M, Burgdorf KS, Manichanh C, et al. A human gut microbial gene catalogue established by metagenomic sequencing. Nature. 2010:464(7285):59-65. doi:10.1038/nature08821.

7. Clauss M, Hume ID, Hummel J. Evolutionary adaptations of ruminants and their potential relevance for modern production systems. Animal. 2010;4(7): 979-92. doi:10.1017/S1751731110000388.

8. Ley RE, Turnbaugh PJ, Klein S, Gordon Jl. Microbial ecology: human gut microbes associated with obesity. Nature. 2006;444(7122):1022-3. doi:10.1038/4441022a.

9. Stevens CE, Hume ID. Contributions of microbes in vertebrate gastrointestinal tract to production and conservation of nutrients. Physiol Rev. 1998;78(2):393-427.

10. Coleman GS. The rate of uptake and metabolism of starch grains and cellulose particles by Entodinium species, Eudiplodinium maggii, some other entodiniomorphid protozoa and natural protozoal populations taken from the ovine rumen. J Appl Bacteriol. 1992;73(6):507-13.

11. Hobson PN, Stewart CS. The Rumen Microbial Ecosystem. London: Chapman + Hall; 1997.

12. Mackie Rl. Mutualistic fermentative digestion in the gastrointestinal tract: diversity and evolution. Integrative Comparative Biol. 2002;42(2):319-26. doi:10.1093/icb/42.2.319.

13. Weimer PJ, Russell JB, Muck RE. Lessons from the cow: what the ruminant animal can teach us about consolidated bioprocessing of cellulosic biomass. Bioresour Technol. 2009;100(21):5323-31. doi:10.1016/j.biortech. 2009.04.075.

14. Edwards EJ, McEwan RN, Travis JA, John WR. 165 rDNA library-based analysis of ruminal bacterial diversity. Antonie Van Leeuwenhoek. 2004;86(3):263-81.

15. Das AK, Sharma D, Kumar N. Buffalo genetic resources in India and their conservation. Buffalo Bull. 2008;27(4):265-8.

16. Martin C, Morgavi DP, Doreau M. Methane mitigation in ruminants: from microbe to the farm scale. Animal. 2010;4(3):351-65.

17. Foley PA, Kenny DA, Callan JJ, Boland TM, O'Mara FP. Effect of DL-malic acid supplementation on feed intake, methane emission, and rumen 
fermentation in beef cattle. J Anim Sci. 2009;87(3):1048-57. doi:10.2527/jas. 2008-1026.

18. Storm E, Orskov ER, Smart R. The nutritive value of rumen micro-organisms in ruminants. 2. The apparent digestibility and net utilization of microbial $\mathrm{N}$ for growing lambs. Br J Nutr. 1983;50(2):471-8.

19. Morrison M, Pope PB, Denman SE, McSweeney CS. Plant biomass degradation by gut microbiomes: more of the same or something new? Curr Opin Biotechnol. 2009;20(3):358-63. doi:10.1016/j.copbio.2009.05.004.

20. Wilson DB. Microbial diversity of cellulose hydrolysis. Curr Opin Microbiol. 2011;14(3):259-63. doi:10.1016/j.mib.2011.04.004.

21. Shanks OC, Kelty CA, Archibeque S, Jenkins M, Newton RJ, McLellan SL, et al. Community structures of fecal bacteria in cattle from different animal feeding operations. Appl Environ Microbiol. 2011;77(9):2992-3001. doi:10.1128/AEM.02988-10.

22. Pedros-Alio C. Genomics and marine microbial ecology. Int Microbiol. 2006;9(3):191-7.

23. von Mering C, Hugenholtz P, Raes J, Tringe SG, Doerks T, Jensen LJ, et al. Quantitative phylogenetic assessment of microbial communities in diverse environments. Science. 2007;315(5815):1126-30. doi:10.1126/science. 1133420.

24. Achenbach LA, Coates JD. Disparity between bacterial phylogeny and physiology - comparing 165 rRNA sequences to assess relationships can be a powerful tool, but its limitations need to be considered. ASM News. 2000;66:714-5

25. Meyer F, Paarmann D, D'Souza M, Olson R, Glass EM, Kubal M, et al. The metagenomics RAST server - a public resource for the automatic phylogenetic and functional analysis of metagenomes. BMC Bioinformatics. 2008:9:386. doi:10.1186/1471-2105-9-386.

26. Park BH, Karpinets TV, Syed MH, Leuze MR, Uberbacher EC. CAZymes Analysis Toolkit (CAT): web service for searching and analyzing carbohydrate-active enzymes in a newly sequenced organism using CAZy database. Glycobiology. 2010;20(12):1574-84. doi:10.1093/glycob/cwq106.

27. Parks $\mathrm{DH}$, Beiko RG. Identifying biologically relevant differences between metagenomic communities. Bioinformatics. 2010;26(6):715-21. doi:10.1093/bioinformatics/btq041.

28. Hammer $\varnothing$, Harper DAT, Ryan PD. PAST: Paleontological statistics software package for education and data analysis. Palaeontologia Electronica. 2001;4(1):1-9.

29. Zhou M, Chung YH, Beauchemin KA, Holtshausen L, Oba M, McAllister TA, et al. Relationship between rumen methanogens and methane production in dairy cows fed diets supplemented with a feed enzyme additive. J Appl Microbiol. 2011;111(5):1148-58

30. McCann JC, Wickersham TA, Loor JJ. High-throughput Methods Redefine the Rumen Microbiome and Its Relationship with Nutrition and Metabolism. Bioinformatics Biol Insights. 2014;8:109-25. doi:10.4137/BBI.S15389.

31. Jami E, White BA, Mizrahi I. Potential role of the bovine rumen microbiome in modulating milk composition and feed efficiency. PLoS One. 2014;9(1): e85423. doi:10.1371/journal.pone.0085423.

32. Li M, Penner GB, Hernandez-Sanabria E, Oba M, Guan LL. Effects of sampling location and time, and host animal on assessment of bacterial diversity and fermentation parameters in the bovine rumen. J Appl Microbiol. 2009; 107(6):1924-34. doi:10.1111/j.1365-2672.2009.04376.x.

33. Pitta DW, Pinchak E, Dowd SE, Osterstock J, Gontcharova V, Youn E, et al. Rumen bacterial diversity dynamics associated with changing from bermudagrass hay to grazed winter wheat diets. Microb Ecol. 2010;59(3): 511-22. doi:10.1007/s00248-009-9609-6.

34. Patel V, Patel AK, Parmar NR, Patel AB, Reddy B, Joshi CG. Characterization of the rumen microbiome of Indian Kankrej cattle (Bos indicus) adapted to different forage diet. Appl Microbiol Biotechnol. 2014;98(23):9749-61. doi:10.1007/s00253-014-6153-1.

35. Ochman H, Worobey M, Kuo CH, Ndjango JB, Peeters M, Hahn BH, et al. Evolutionary relationships of wild hominids recapitulated by gut microbial communities. PLoS Biol. 2010;8(11):e1000546. doi:10.1371/journal.pbio. 1000546.

36. Arumugam M, Raes J, Pelletier E, Le Paslier D, Yamada T, Mende DR, et al. Enterotypes of the human gut microbiome. Nature. 2011;473(7346):174-80. doi:10.1038/nature09944.

37. Parmar NR, Solanki JV, Patel AB, Shah TM, Patel AK, Parnerkar S, et al. Metagenome of Mehsani buffalo rumen microbiota: an assessment of variation in feed-dependent phylogenetic and functional classification. J Mol Microbiol Biotechnol. 2014;24(4):249-61. doi:10.1159/000365054.
38. Brulc JM, Antonopoulos DA, Miller ME, Wilson MK, Yannarell AC, Dinsdale $E A$, et al. Gene-centric metagenomics of the fiber-adherent bovine rumen microbiome reveals forage specific glycoside hydrolases. Proc Natl Acad Sci U S A. 2009;106(6):1948-53. doi:10.1073/pnas.0806191105.

39. Parnell JA, Reimer RA. Prebiotic fiber modulation of the gut microbiota improves risk factors for obesity and the metabolic syndrome. Gut microbes. 2012;3(1):29-34. doi:10.4161/gmic.19246.

40. Thomas F, Hehemann JH, Rebuffet E, Czizek M, Michel G. Environmental and gut bacteroidetes: the food connection. Frontiers Microbiol. 2011;2:93. doi: 10.3389/fmicb.2011.00093.

41. Dehority BA. Effects of microbial synergism on fibre digestion in the rumen. Proc Nutr Soc. 1991;50(2):149-59.

42. Strobel HJ. Vitamin B12-dependent propionate production by the ruminal bacterium Prevotella ruminicola 23. Appl Environ Microbiol. 1992:58(7):2331-3

43. O'Neill BF, Deighton MH, O'Loughlin BM, Mulligan FJ, Boland TM, O'Donovan M, et al. Effects of a perennial ryegrass diet or total mixed ration diet offered to spring-calving Holstein-Friesian dairy cows on methane emissions, dry matter intake, and milk production. J Dairy Sci. 2011;94(4): 1941-51. doi:10.3168/jds.2010-3361.

44. Kong Y, Teather R, Forster R. Composition, spatial distribution, and diversity of the bacterial communities in the rumen of cows fed different forages. FEMS Microbiol Ecol. 2010;74(3):612-22. doi:10.1111/j.1574-6941.2010.00977.x.

45. Mahowald MA, Rey FE, Seedorf H, Turnbaugh PJ, Fulton RS, Wollam A, et al. Characterizing a model human gut microbiota composed of members of its two dominant bacterial phyla. Proc Natl Acad Sci U S A. 2009;106(14):585964. doi:10.1073/pnas.0901529106.

46. Gruninger RJ, Sensen CW, McAllister TA, Forster RJ. Diversity of rumen bacteria in canadian cervids. PLoS One. 2014;9(2), e89682. doi:10.1371/ journal.pone.0089682.

47. Turnbaugh PJ, Ley RE, Mahowald MA, Magrini V, Mardis ER, Gordon Jl. An obesity-associated gut microbiome with increased capacity for energy harvest. Nature. 2006;444(7122):1027-31. doi:10.1038/nature05414.

48. Fernando SC, Purvis 2nd HT, Najar FZ, Sukharnikov LO, Krehbiel CR, Nagaraja $\mathrm{TG}$, et al. Rumen microbial population dynamics during adaptation to a high-grain diet. Appl Environ Microbiol. 2010;76(22):7482-90. doi:10.1128/ AEM.00388-10.

49. Wells JE, Russell JB, Shi Y, Weimer PJ. Cellodextrin efflux by the cellulolytic ruminal bacterium Fibrobacter succinogenes and its potential role in the growth of nonadherent bacteria. Appl Environ Microbiol. 1995;61(5):1757-62.

50. Allison MJ, Bryant MP. Biosynthesis of branched-chain amino acids from branched-chain fatty acids by rumen bacteria. Arch Biochem Biophys. 1963; 101:269-77.

51. Blackburn TH, Hungate RE. Succinic acid turnover and propionate production in the bovine rumen. Appl Microbiol. 1963;11:132-5.

52. Fron MJ, Boling JA, Bush LP, Dawson KA. Sulfur and nitrogen metabolism in the bovine fed different forms of supplemental sulfur. J Anim Sci. 1990;68(2):543-52

53. Storm E, Orskov ER. The nutritive value of rumen micro-organisms in ruminants. 1. Large-scale isolation and chemical composition of rumen micro-organisms. Br J Nutr. 1983;50(2):463-70.

54. Allen MS. Relationship between fermentation acid production in the rumen and the requirement for physically effective fiber. J Dairy Sci. 1997;80(7): 1447-62. doi:10.3168/jds.50022-0302(97)76074-0.

55. Lailer PC, Dahiya SS, Lal D, Chauhan TR. Rumen fermentation patter in buffaloes fed complete feed block. Indian J Animal Nut. 2011;28:177-80,

56. Bergman EN. Energy contributions of volatile fatty acids from the gastrointestinal tract in various species. Physiol Rev. 1990;70(2):567-90.

57. Reichardt N, Duncan SH, Young P, Belenguer A, McWilliam Leitch C, Scott $\mathrm{KP}$, et al. Phylogenetic distribution of three pathways for propionate production within the human gut microbiota. ISME J. 2014;8(6):1323-35. doi:10.1038/ismej.2014.14.

58. Sergeant MJ, Constantinidou C, Cogan TA, Bedford MR, Penn CW, Pallen MJ. Extensive microbial and functional diversity within the chicken cecal microbiome. PLoS One. 2014;9(3):e91941. doi:10.1371/journal.pone.0091941.

59. Macy JM, Probst I. The biology of gastrointestinal bacteroides. Annu Rev Microbiol. 1979;33:561-94. doi:10.1146/annurev.mi.33.100179.003021.

60. Lettat A, Hassanat F, Benchaar C. Corn silage in dairy cow diets to reduce ruminal methanogenesis: effects on the rumen metabolically active microbial communities. J Dairy Sci. 2013;96(8):5237-48. doi:10.3168/jds.2012-6481. 
61. Li CJ, Li RW. Butyrate induced cell cycle arrest in bovine cells through targeting gene expression relevant to DNA replication apparatus. Gene Regulation Systems Biol. 2008;2:113-23.

62. van Kessel JAS, Russell JB. The effect of pH on ruminal methanogenesis. FEMS Microbiol Ecol. 1996;20(4):205-10. doi:10.1111/j.1574-6941.1996. tb00319.x.

63. Wright ADG, Kennedy P, O'Neill CJ, Toovey AF, Popovski S, Rea SM, et al. Reducing methane emission in sheep by immunization against rumen methanogens. Vaccine. 2004;22:3976-85.

64. Mastepanov M, Sigsgaard C, Dlugokencky EJ, Houweling S, Strom L, Tamstorf MP, et al. Large tundra methane burst during onset of freezing. Nature. 2008;456(7222):628-30. doi:10.1038/nature07464.

65. Johnson KA, Johnson DE. Methane emissions from cattle. J Anim Sci. 1995; 73(8):2483-92.

66. Patel DD, Patel AK, Parmar NR, Shah TM, Patel JB, Pandya PR, et al. Microbial and Carbohydrate Active Enzyme profile of buffalo rumen metagenome and their alteration in response to variation in the diet. Gene. 2014;545(1): 88-94. doi:10.1016/j.gene.2014.05.003.

67. Dodd D, Kocherginskaya SA, Spies MA, Beery KE, Abbas CA, Mackie Rl, et al. Biochemical analysis of a beta-D-xylosidase and a bifunctional xylanaseferulic acid esterase from a xylanolytic gene cluster in Prevotella ruminicola 23. J Bacteriol. 2009:191(10):3328-38. doi:10.1128/JB.01628-08.

68. Harmon DL. Dietary influences on carbohydrases and small intestinal starch hydrolysis capacity in ruminants. J Nutr. 1992;122(1):203-10.

Submit your next manuscript to BioMed Central and we will help you at every step:

- We accept pre-submission inquiries

- Our selector tool helps you to find the most relevant journal

- We provide round the clock customer support

- Convenient online submission

- Thorough peer review

- Inclusion in PubMed and all major indexing services

- Maximum visibility for your research

Submit your manuscript at www.biomedcentral.com/submit
Biomed Central 